\title{
Versiones y ediciones de los Ejercicios Espirituales de San Ignacio. México, 1596-1856
}

\author{
Mónica Hidalgo Pego*
}

Recibido: 15 de abril de 2020

Dictaminado: 26 de agosto de 2020

Aceptado: 09 de octubre de 2020

\section{RESUMEN}

Con la intención de contribuir a los trabajos sobre la difusión y la recepción de un autor y su obra, el presente artículo tiene como finalidad presentar los primeros resultados de una investigación de largo aliento sobre Ignacio de Loyola y su obra Ejercicios Espirituales, en un espacio bien definido, México, en el período virreinal y el siglo XIX. La periodización del trabajo está limitada por la edición más antigua localizada, 1596, y la tercera supresión de la Compañía de Jesús en México. El texto se construyó a partir de los ejemplares existentes en las bibliotecas de la República Mexicana. Además de la investigación sobre los ejercicios del santo vasco, se da cuenta de algunos escritores jesuitas que trataron diferentes aspectos relacionados con los ejercicios ignacianos. Hasta el momento, los resultados de la investigación mostraron una difusión, al parecer, poco numerosa del libro de los ejercicios, a diferencia de las obras de sus hermanos de orden. En cuanto a la recepción de los libros y de la 
práctica de los ejercicios pudo advertirse una amplia recepción no sólo entre los eclesiásticos, sino en las mujeres, monjas, e incluso laicos.

Palabras clave: ejercicios espirituales, ediciones, versiones, bibliotecas, ejercitantes, difusión, recepción.

\title{
Versions and editions of the Spiritual Exercises of Saint Ignatius. Mexico, 1596-1856
}

\begin{abstract}
With the intention of contributing to the works on the dissemination and reception of an author and his work, this article aims to present the first results of a long-term investigation on Ignacio de Loyola and his work Spiritual Exercises, in a space well defined, Mexico, in the viceregal period and the 19th century. The periodization of the work is limited by the oldest edition located, 1596 and the third suppression of the Society of Jesus in Mexico. The text was constructed from the existing copies in the libraries of the Mexican Republic. In addition to the research on the exercises of the Basque saint, he is aware of some Jesuit writers who treated different aspects related to the Ignatian exercises. So far, the results of the investigation showed an apparently small diffusion of the book of exercises, unlike the works of his brothers of order, as far as the reception of the books and the practice of the exercises could be noticed a wide reception not only among ecclesiastics, but among women, nuns, and even lay people.
\end{abstract}

Key words: spiritual exercises, editions, versions, libraries, exercisers, broadcast, reception.

Los Ejercicios son uno de los libros más venerables salidos de manos de hombres, porque si la Imitación de Cristo ha enjugado más lágrimas, los Ejercicios han producido más conversiones y más santos.

De Causette, Mélanges oratoires, París, 1, 1876, p. I.

\section{INTRODUCCIÓN}

$\mathrm{E}^{\mathrm{n}}$ el Antiguo Régimen el interés por el estudio de los autores y su obra escrita proliferó en los siglos XVII y XVIII; esta tarea fue emprendida por los bibliófilos que publicaron catálogos y monografías. En el caso concreto de la Compañía de Jesús, Pedro de Ribadeneyra publicó, en 1608, Illustrius 
scriptorum religionis Societatis Iesu catalogus, (Amberes, Plantin), bibliografía especializa de escritores jesuitas; posteriormente, Philippe Alegambre inicio en 1643 la serie Bibliotheca scriptorum S.I., donde se recopilaban de manera paulatina las ediciones de nuevos autores ignacianos. La tarea emprendida por Rivadeneyra continúa hasta nuestros días, aunque la labor se diversificó hacia trabajos relativos a un solo autor o a escritores de un solo país; en México se cuenta con los textos de Francisco Zambrano, José Casillas y Juan B. Íñiguez. ${ }^{1}$ Actualmente, los hijos de Loyola están trabajando en la página web Societatis Iesu Biblithecae Hispanicae et Americanae (SIBHA) con la finalidad de reconstruir el legado bibliográfico y cultural de las bibliotecas jesuíticas españolas y americanas. El esfuerzo emprendido por los jesuitas no es nuevo, ya que existen otras iniciativas como el Catálogo Colectivo del Patrimonio Bibliográfico Español (CCBR) o en el caso de México, el trabajo efectuado por la asociación civil ADABI (Apoyo al Desarrollo de Archivos Bibliotecas de México).

Además de las mencionadas iniciativas, las actuales bibliotecas y archivos son de suma relevancia para acercarse al mundo de los escritores y sus obras, ya que dichos espacios han estado ligados al desarrollo y difusión de la cultura, convirtiendo a la cultura $\mathrm{y}$, especialmente al libro, en objeto de estudios literarios, bibliográficos e históricos que se valen de una metodología propia para la construcción de sus investigaciones. En el caso de las dos últimas disciplinas, los especialistas se han valido de las contribuciones hechas por la bibliografía material anglosajona inaugurada por Ronald B. McKerrow, A.W. Pollard y W.W. Greg, MaKerrow, ${ }^{2}$ la cual publicó en 1927 Introducción a la vida material. ${ }^{3}$ La obra es un manual sobre ediciones, impresiones, corrección de pruebas, datación cierta o falsa, descripción del libro impreso, etcétera.

De igual manera, los investigadores se han acercado a las aportaciones de la historiografía francesa de los Anales iniciada con la aparición de La historia del libro, de Lucien Febvre y Henri Jean Martin ${ }^{4}$ y continuada por Roger Chartier, Robert Darton, Fréderic Barbier, entre otros. Sus obras han puesto especial énfasis en la historia de la edición y en la historia de la lectura. La primera

1 Para conocer las ediciones de catálogos bio-bibliográficos reconocidos por la Compañía de Jesús debe consultarse el Diccionario de la Compañia de Jesús, impreso en 2001 y puesto ahora en pdf en la página del Archivum Romanum Societatis Iesu, http://www.sjweb.info/ arsi/Digitalized_Books.cfm

2 García, "Bibliografía material para el conocimiento y trasmisión de las fuentes bibliográficas novohispanas", 2020.

3 La primera impresión lleva por título An Introduction to Bibliography for Literary Students, Oxford, Clarendon Press.

$4 \quad$ La primera edición bajo el título L'apparition du livre fue publicada en París por Albin Michael en 1958. Prontamente fue traducida al español publicándose en México por la Unión Tipográfica Hispano Americana, en 1962. 
analiza la circulación de libros, los talleres tipográficos, la comercialización, la producción impresa, así como a los sujetos que intervinieron en dichas actividades, mientras que la segunda se ha encargado de las representaciones, las prácticas y la recepción de los lectores. ${ }^{5}$

México no ha sido ajeno a las aportaciones de la historiografía francesa, por lo que en los últimos años los investigadores del libro se han dedicado a analizar las imprentas, los impresores, las bibliotecas, la historia del libro en México, la circulación de libros, entre otros tópicos. ${ }^{6}$ En cuanto al tema de la difusión y la recepción, México no ha corrido con la misma suerte, pues son pocos los trabajos realizados como el ya citado de Gómez o el escrito por Enrique González sobre la difusión y la recepción de la obra de Vives. ${ }^{7}$ Así pues, resulta de relevancia continuar con las investigaciones relativas a la recepción y difusión desde el ámbito mexicano.

Con dicha intención se decidió iniciar una investigación de largo aliento sobre Ignacio de Loyola y su obra Ejercicios Espirituales, en un espacio bien definido, México: período virreinal y siglo XIX, cuyos resultados preliminares son dados a conocer en el presente texto. Para su desarrollo se pensó en efectuar una primera periodización limitada por los años 1596 y 1856 . El primer año corresponde a la edición más antigua localizada hasta el momento en los repositorios mexicanos y, el segundo, al año de la tercera supresión de la Compañía de Jesús en México.

Para darme una idea sobre la obra ignaciana en esta primera etapa se recurrió a la búsqueda de ejemplares existentes en las bibliotecas de la República Mexicana, dejando para una segunda, el examen de los repertorios bibliográficos jesuitas, de los que se ha dado cuenta, así como de otras bibliografías o catálogos del Antiguo Régimen y de la centuria decimonónica.

La búsqueda del material se efectuó en diversos catálogos bibliográficos, de los que se dará cuenta en las siguientes páginas, encontrando que sólo en nueve bibliotecas existen ejemplares del libro del Santo, no obstante, y tras el acercamiento a los acervos y sus ejemplares ha sido posible no sólo conocer las ediciones resguardadas, sino también, sus diferentes títulos, los editores,

5 Algunos títulos que pueden revisarse son los siguientes: Chartier, El mundo como representación. Estudios sobre historia cultural, 1999; Chartier, "El libro. Un cambio de perspectiva", 1978-1980; Barbier, Historia del Libro, Madrid, 2015 y Darton, El coloquio de los lectores. Ensayos sobre autores, manuscritos, editores y lectores, 2003.

6 Por el momento no he localizado un balance historiográfico que dé cuenta de los trabajos efectuados en México, por ello remito al apartado bibliográfico del libro de Gómez, La circulación de las ideas. Bibliotecas particulares en una época revolucionaria. Nueva España, 1750-1819, 2019.

7 González, Una república de lectores. Difusión y recepción de la obra de Juan Luis Vives, 2007. 
los países de origen, el año de publicación, los grabados que contienen, las instituciones de procedencia, así como a los ejercitantes.

Ala par que se realizaba la investigación y cotejo se localizaron diversas obras escritas por otros jesuitas, las cuales tratan diferentes aspectos relacionados con los ejercicios ignacianos como las meditaciones o las lecciones espirituales, de éstas también se habla, pero circunscribiendo su estudio a las encontradas en la Biblioteca Nacional de México y en la biblioteca de la Universidad Iberoamericana, debido a que el número de autores y de obras es abundante.

A lo largo del trabajo se busca responder a las siguientes preguntas. ¿Cuáles y cuántos son los ejemplares de los Ejercicios Espirituales que perduran hasta nuestros días en las bibliotecas mexicanas? ¿Se publicó el libro de Ignacio y de sus hermanos de orden en México? ¿A qué instituciones o personas pertenecieron antes de llegar a las bibliotecas que los resguardan en la actualidad? ¿Quiénes fueron los autores de los libros de meditaciones o adaptaciones del texto ignaciano? ¿Qué propósitos persiguieron al acomodarlos? ¿A qué comunidades o personas estaban dirigidos?

Para contestar a las interrogantes planteadas, el texto se divide en cinco apartados. En el primero se hace una breve historia del proceso de elaboración del libro de los Ejercicios Espirituales y de la publicación príncipe de los textos conocidos como Vulgata y Autógrafo. En el segundo se realiza un acercamiento cuantitativo los ejemplares del libro existentes en algunas bibliotecas europeas y americanas; en el tercero se da cuenta del número de ejemplares ubicados en las bibliotecas mexicanas y se examinan algunas características de los libros. En el cuarto se habla de los autores y textos elaborados por otros jesuitas y, en el último apartado, se hace un recuento de las corporaciones que contaron con el libro del santo y de otros jesuitas, asi como del tipo de ejercitantes.

\section{BREVE HISTORIA DE LA ESCRITURA DEL LIBRO EJERCICIOS ESPIRITUALES DE SAN IGNACIO}

Los ejercicios de Ignacio de Loyola no fueron pensados para publicarse, pues el santo consideraba que para conocerlos debían ser practicados, tal y como lo hizo con sus primeros compañeros, ${ }^{8}$ pero de alguna manera, nos dice Enrique García Hernán,

8 En los años subsecuentes a su conversión, Ignacio decidió seguir a Dios sólo, no obstante, pronto se fue dando cuenta que, en grupo, el auxilio de las ánimas era mayor, por ello, desde 1525 durante su residencia en Barcelona, comenzó a "desplegar una tendencia societaria", la cual lo acompañó toda su vida. Los primeros en unirse a él fueron Calixto de Sá, Juan de Arteaga, Lope de Cáceres y Juan Reinalde, este primer grupo se disolvió con la partida del futuro santo a París en 1528. En dicha ciudad fue donde entre 1528 y 1536 se conformó, como lo indicado la historiografía de la orden, el primer grupo de jesuitas de la Compañía de 
Ignacio perdió el control de los ejercicios, pues los daban incluso gente que no era jesuita. Hubo abusos, confusiones, tergiversaciones y engaños. Había que poner remedio, sobre todo porque las críticas arreciaban por todas partes, así que lo mejor era poner en circulación una versión oficial. ${ }^{9}$

Para llegar a esa versión final se debió recorrer un largo camino, el cual inició en 1521 en Loyola, a donde Ignacio se dirigió para recuperarse de la herida recibida en una pierna en la batalla de Pamplona: ${ }^{10}$ durante ese tiempo se dedicó a la lectura, reflexión y resumen de las obras que lo habían llevado a la conversión. ${ }^{11}$ En 1522 estando ya en Manresa, provincia de Cataluña, Ignacio concibió el esquema de sus ejercicios quedando

más ceñidos cuanto a la duración, poco más o menos de un mes; más articulados cuanto a la materia, mediante las prácticas de la purgación perfecta y el concentramiento de toda la perfección en el conocimiento y amor del Verbo hecho carne; más conscientes y consecuentes en el fin por el cual se hacen, de dominar las afecciones desordenadas que impiden el hallazgo y el cumplimiento perfecto de la divina voluntad en la propia vida, más iluminados y seguros finalmente, en

Jesús aprobada en 1540. Sus integrantes fueron Pedro Fabro, Francisco Xavier, Diego Laínez, Simón de Rodríguez, Alfonso Salmerón, Nicolás Bobadilla, el francés Paschase Bröet, Jean Baptiste Cordure, Diego Hoces y Claudio Jay. Todos ellos son conocidos como los primeros compañeros de Ignacio, dicha expresión aparece en la Autobiografía del santo y en su Diccionario espiritual. García de Castro, "Los primeros de París. Amistad, carisma y pauta", pp. 253- 254.

9 García Hernán, indica que algunos personajes argumentaban que los ejercicios llevaban al alumbradismo o iluminismo, para terminar con esa creencia era necesario obtener la aprobación papal. Aun después de obtenida, en la corte española, hacia 1553, inició una abierta oposición a los ejercicios capitaneada principalmente por los dominicos. Pascual Mancio, quien fue el principal opositor, señaló, como se había hecho anteriormente, que estos ejercicios introducían al alumbradismo "al proponer la indiferencia de todas las criaturas". Asimismo, pensó que, si hubieran sido tan ortodoxos, el texto publicado se hubiera vendido a cualquiera en lugar de repartir los ejemplares entre los jesuitas y algunas personas escogidas, lo cual parecía ocultar algo. Para mostrar que no era así, Ignacio envío a Felipe II un libro de los ejercicios y buscó la ayuda del cardenal infante de Portugal, de los doctores Navarro, Torres y Ávila y de los dominicos letrados para lograr su aprobación. García, Ignacio de Loyola, pp. 383-386.

10 En 1521, Francisco I de Francia planeaba invadir Navarra, por lo que el duque de Nájera, virrey de dicho reino, solicitó tropas auxiliares de Guipúzcoa para combatir a los franceses en Pamplona, entre esas tropas se encontraba Ignacio, junto con su hermano Martín, quien comandaba una de ellas. Leturia, "Datos inéditos sobre la acción militar de Íñigo de Loyola en Pamplona", p. 436.

11 Dichas obras fueron las siguientes: Vitta Christi de Landolfo de Sajonia, traducido al castellano por el franciscano fray Antonio de Montesinos, versión leída por Íñigo. Además de Flos Sanctorum o Vida de los Santos de Jacobo de Varazze. Ejercitatorio de García de Cisneros y las Sagradas Escrituras. 
la dirección de aquella luz soberana con la que Ignacio se siente ahora llevado, como un niño por su maestro, en el discernimiento de los espíritus y en los pasos todos de la vida espiritual. ${ }^{12}$

Luego Íñigo practicó los ejercicios en la cueva de Manresa y escribió algunas notas, dando a la luz el primer bosquejo del libro de los ejercicios. De Manresa se trasladó a Barcelona, después a Tierra Santa y, finalmente, en 1524 regresó a Barcelona a tomar clases en la universidad y posteriormente en la de Alcalá de Henares; estando en esa ciudad fue encarcelado por el Santo Oficio, ya que carecía de estudios y permiso para enseñar. Tras su liberación se fue a Salamanca, donde fue acusado nuevamente por la Inquisición, esta vez por introducir doctrinas peligrosas, aunque después de pasar tres semanas en prisión fue absuelto. Ignacio decidió entonces abandonar España y dirigirse a París.

La génesis de la composición del libro comenzó precisamente en la ciudad luz, así entre febrero de 1528 y abril de 1535, Ignacio corrigió el texto, lo mostró a sus compañeros del voto de Montmartre, ${ }^{13}$ y comenzó la traducción del castellano al latín; el segundo traductor y primer corrector fue Pedro Fabro. La segunda etapa de redacción comprende de 1536 a 1541, ${ }^{14}$ y consta de dos fases; la primera fue escrita en Italia y va de 1536 a mediados de 1539, a lo largo de esos años Ignacio sigue introduciendo cambios y afinando el escrito. La segunda fase, ya en Roma, inicia en la segunda mitad de 1539 y culmina en junio de 1541, durante ese período Fabro es sustituido por Alfonso Salmerón, quien se convierte en el segundo corrector y en el tercer traductor, a él le tocó mejorar la redacción de las nuevas partes introducidas por Íñigo, además de seis correcciones. Finalmente, entre mayo y junio de 1541, el parmesano

12 Iparraguirre, Práctica de los ejercicios de San Ignacio de Loyola en vida de su autor (15221556), p. 37.

13 El 15 de agosto de 1534, Ignacio de Loyola y siete de sus compañeros, después de reflexiones, meditaciones y oraciones, hicieron votos de pobreza, de peregrinar a Jerusalén y de obedecer al Pontífice Romano. Los votos fueron hechos en la capilla de los mártires ubicada en la colina de Montmartre. Rodríguez, "Peregrinación interior de Pedro Fabro", p. 645.

14 En 1536 ya existían tres copias del texto, la primera es la de 1527, entregada por Ignacio al bachiller Sancho de Frías para que la examinara, al examen se sumaron Fernando Rodríguez de San Isidoro, Alonso Gómez de Paradinas y Francisco de Frías; ello sucedió en Salamanca. La segunda es la de París entregada al inquisidor Valentín Liévin en 1535. La tercera copia de 1736 la hizo para sí el cardenal Gaspar Contarini en Venecia. Arzubialde, Ejercicios Espirituales de San Ignacio. Historia y análisis, p. 40. Sobre los traductores de cada escrito y sobre los cambios habidos en ellos puede consultarse la obra del citado autor, pp. 52 y $59-60$ y el artículo de Calveras, "Estudios sobre la redacción de los textos latinos de los ejercicios anteriores a la Vulgata", pp. 3-99. 
Juan Bautista Viola se hizo cargo de la primera traducción completa de los ejercicios; a dicha copia se le denominó Versio Prima o $\mathrm{P}_{1} \cdot{ }^{15}$

La tercera etapa corresponde a la elaboración de otra copia conocida como Versio Prima $\mathrm{P}_{2}$. En 1547, Juan Alfonso de Polanco introdujo algunas enmiendas que se asemejan casi literalmente a las que hizo en la Vulgata, es decir, en la traducción hecha entre 1546 y 1547 por el humanista Andrés des Freux o Frusio teniendo como base el texto castellano conocido como Autógrafo, del que haremos referencia más adelante, por ello se considera que sus aportaciones a la génesis del libro fueron muy importantes. ${ }^{16}$ Las añadiduras del Polanco fueron decididas o tal vez aceptadas por Ignacio.

Gracias a la intervención de Francisco de Borja, duque de Gandía, y jesuita a partir de 1546, la $\mathrm{P}_{1}$ y la Vulgata, encuadernadas juntas, fueron aprobadas por el Papa Paulo III mediante breve del 21 de junio de 1548. Para llegar a esta aprobación, Borja envió al deán Roca, su agente en Roma, una carta que debía entregar al pontífice; en ella, Borja le comunicó la muerte de su esposa Leonor, además de informarle que el deán conversaría con su santidad para conseguir la autorización de los ejercicios ignacianos. ${ }^{17}$ Antes de tomar una decisión, el Santo Padre dispuso que los textos fueran examinados por el dominico Egidio Foscarari, quien dio una opinión favorable, empero, el Papa no conforme con ella, encargó a Juan Álvarez de Toledo, cardenal de Burgos y a Felipe Archinto, vicario de Roma, revisar nuevamente el escrito. El primero señaló que el libro le parecía "muy conducente para la salud de las almas", mientras el segundo lo calificó como una obra "digas de todo encomio y muy beneficiosa para la profesión cristiana". ${ }^{18}$

Los comentarios vertidos por los revisores lograron que los textos recibieran el imprimatur. ${ }^{19}$ El texto que se estampó en Roma por Antonio Blado, el 11 de septiembre de 1548, fue la Vulgata con el título Exercitia spiritualia, el tiraje de 500 ejemplares fue costeado por Borja. El jesuita Cándido de Dalmases señala que dicho ejemplar no fue el definitivo - aunque se entregó a los directores de diferentes países - pues sólo se llevó a la imprenta por haberse escrito en un latín elegante. Tampoco la Compañía de Jesús consideró a la Vulgata como el texto definitivo por lo que

Arzubialde, Ejercicios espirituales de S. Ignacio: Historia y análisis, pp. 35-42 y 49-53.

Dalmases, Ignacio de Loyola. Ejercicios Espirituales, pp. 26-28.

García, Ignacio de Loyola, p. 384.

Obras de San Ignacio de Loyola, p. 118.

El imprimatur es únicamente para las obras autorizadas por el papado, ésta debe de estar exenta de errores en materia de doctrina y moral católica. Para la primera edición del libro, Paulo III dejó en manos de Ignacio la elección del impresor, para las subsecuentes impresiones, no se le permitió a Ignacio ni a cualquier otra persona estamparlo sin el consentimiento del futuro santo o de sus sucesores. Ejercicios espirituales de san Ignacio de Loyola, fundador de la Compañia de Jesús en su texto original, pp. 5-6. 
La Congregación General V (1592-1593), nombró [...] una comisión encargada de cotejar la Vulgata con el Autógrafo. Y aunque observó que, por lo general, la Vulgata era fiel al original castellano, la comisión redactó una serie de notas en las que se adaptaba la traducción al Autógrafo. Por respecto a la Vulgata, el General P. Claudio Acquaviva, dispuso que tales correcciones no se introdujesen en el propio texto, sino al final del mismo. ${ }^{20}$

En vida del santo se hicieron otras dos ediciones de la Vulgata, una impresa en Coimbra en 1553 por Juan Barrero, la cual fue reimpresa en el mismo año por comisión del autor. Tras su muerte se publicaron otras tres en Burgos, Sevilla y Valencia en los años de 1574, 1587 y 1599, respectivamente. ${ }^{21}$ Con los años se hicieron nuevas reimpresiones y otras traducciones latinas, siendo la más importante la elaborada en el período de la primera restauración de la Compañía de Jesús ${ }^{22}$ por el vigésimo primer general de la Compañía, Juan Felipe Roothaan. Su objetivo era revitalizar los ejercicios espirituales "dándoles un lugar central en la formación y vida de los jesuitas". ${ }^{23}$ El general, tomando en cuenta las diferencias existentes entre la Vulgata y el Autógrafo, decidió volver a traducir los ejercicios al latín. Su propósito no era remplazar la Vulgata, por lo que publicó el trabajo de Frusio junto con el suyo en columnas paralelas. El libro vio la luz en 1835 y se reimprimió en Londres en 1847 y en Baltimore en $1850 .^{24}$

El Autógrafo, es decir, la versión castellana de los ejercicios espirituales se llamó así no por haber sido escrita por Ignacio, sino por contener 32 añadiduras de su puño y letra; ${ }^{25}$ el manuscrito autógrafo de 1541 no se conserva, pero sí el elaborado, según el padre José Calveras, por el portugués Bartolomé Ferrao, secretario de la orden entre 1545 y 1548 . Se cree que el texto fue escrito en 1544, debido a las adiciones, posiblemente hechas por Bröet.

La Compañía de Jesús consideró al Autógrafo como su texto básico, no obstante, su publicación fue tardía estampándose por primera vez en 1615 en la ciudad eterna (Roma) por orden del secretario de la Compañía, Bernardo de Angelis. ${ }^{26}$ Su publicación tardía indica Calveras, pudo deberse a la "parsimonia

20 Dalmases, Ignacio de Loyola. Ejercicios Espirituales, p. 29.

21 Iparraguirre, Orientaciones bibliográficas sobre San Ignacio de Loyola, pp. 161-162.

22 La Compañía de Jesús fue extinguida por el Papa Clemente XIV en 1773. En 1814, el pontífice Pio VII, decidió llevar a cabo su restauración. Al respecto puede consultarse el siguiente libro: Giménez, La Compañia de Jesús, del exilio a la restauración. Diez estudios, 2017.

23 Diccionario histórico de la Compañia de Jesús, p. 3495.

24 Biblioteca católica digital "Los Ejercicios Espirituales de San Ignacio" https://www. feybiblia.com/details?q=Ejercicios-Espirituales-de-San-Ignacio.

25 Calveras indica que la lista de añadiduras puede verse en MHSI, Exercitia², pp. 93-94.

26 Existen además otros cinco manuscritos castellanos. Pueden consultarse en Dalmases, pp. 21-24. 
con que San Ignacio quiso que se distribuyese aun el mismo texto latino, impreso en 1548”, pues juzgaba que la obra debía ser utilizada únicamente por los futuros directores de ejercicios, y a "los problemas que creaba la publicación de libros en lengua vulgar, sobre todo en España, donde los ejercicios fueron precisamente objeto de fuertes ataques". ${ }^{27}$ No se ha encontrado hasta el momento ninguna noticia que sugiera la prohibición en España de imprimir el libro en su versión castellana, no obstante, debe indicarse que en los siglos XVI y XVII, la península ibérica tuvo problemas para llevar a cabo la producción de libros tales como el escaso número de talleres, prensas y materias primas; lo mismo se puede observar para la Nueva España. Aunado a dichos factores, la Corona española controló los privilegios de impresión y el comercio de libros. $^{28}$

\section{UN ACERCAMIENTO CUANTITATIVO LOS EJEMPLARES DEL LIBRO. ENTre Europa y AMÉrica}

Para darse una idea sobre la actual existencia de ediciones del libro del santo, se efectuó una revisión de varios catálogos extranjeros de bibliotecas nacionales de Francia, España, Gran Bretaña, Bélgica, ciudad del Vaticano, Perú Colombia y Argentina, así como de los catálogos generales Europeana y CCBR. Después de la exploración se localizaron 28 diferentes impresiones o reimpresiones del libro de los ejercicios en latín y siete en castellano. De la versión latina ocho corresponden al siglo Xv, nueve al seiscientos, dos al siglo XVIII y 10 a la centuria decimonónica. ${ }^{29}$ En cuanto a las ediciones castellanas se conserva la de 1615, tres del siglo XVIII, y otra de 1800, seguramente existieron otras impresiones, pero por el momento no han podido localizarse; habrá que revisar los catálogos o repertorios de los que se ha hecho mención. La ausencia de ejemplares publicados después de 1749 se debe a que los escritos de Ignacio quedaron proscritos en el índice de los libros prohibidos y expurgados de 1794.

En las bibliotecas mexicanas se conservan 10 libros diferentes de la edición latina y cuatro de la castellana, ninguna difiere de las localizadas en los repositorios extranjeros. Así pues, el número de ejemplares de los ejercicios de Ignacio encontrados en las bibliotecas mexicanas es equiparable con el

27 Dalmases, Ignacio de Loyola. Ejercicios Espirituales, p. 19.

28 Moreno, La librería de Luis Mariano de Ibarra. Ciudad de México, 1730-1750, México, 2009

29 Los años de edición de los textos latinos son los siguientes: 1548, 1553, 1556, 1563, 1574 , $1576,1586,1599,1600,1606,1610,1615,1635,1638,1644,1676,1689,1732,1733,1800$, 1829, 1833, 1834, 1837, 1838, 1841, 1847, 1848. Los años de las impresiones castellanas son los siguientes: 1615, 1732, 1733, 1735, 1749, 1800, 1833, 1838, 183, 1848, 1852. 
de otras bibliotecas o repositorios extranjeros, como el catálogo CCBR que registra tres ediciones en castellano y 27 en latín. ${ }^{30}$

Para explicar las diferencias entre las ediciones localizadas en el extranjero y las mexicanas deben tomarse en consideración algunos factores como la falta de acceso a algunas bibliotecas privadas que en muchas ocasiones conservan verdaderos tesoros bibliográficos, al trasiego de libros entre países, lo cual ha llevado a que las obras terminen en colecciones privadas.

Otro posible factor son los destinatarios de este libro. Como habían advertido Ignacio, Polanco y Aquaviva, al principio el texto sólo era para directores y futuros directores de ejercicios, por esa razón no era necesario contar con un número elevado de ejemplares, y aunque en la primera edición de 1615 se tiraron 500, éstos sólo fueron repartidos entre algunos personajes importantes allegados a la orden, y los demás entre los jesuitas directores. Posteriormente se autorizó que los ejercicios fueran dados en casas ajenas a los colegios o casas ignacianas, pero siempre por personas eclesiásticas de renombre o por miembros de otras órdenes regulares. Dicha medida, aunque amplió el número de destinatarios, no llevó a la impresión a destajo del librito de Ignacio, como se ha constatado, ni tampoco a producir un número excesivo de textos, pues los tirajes eran de entre 200 y 500 ejemplares. Así pues, la obra de Íñigo estuvo destinado a un grupo muy reducido los directores jesuitas y algunos eclesiásticos. Sobre este aspecto será necesario en un futuro poder contabilizar a los directores de ejercicios en Nueva España y México para afirmar o negar la consideración hecha.

Otro elemento a destacar es el concierne a la circulación de libros entre España y Nueva España, lo cual pudo limitar o favorecer la llegada de determinadas ediciones del libro. El arribo de obras al territorio novohispano estuvo condicionado por el monopolio comercial ejercido desde la península, cuestión que impidió a otros países intercambiar libros de forma legal con las colonias españolas, ${ }^{31}$ además de que ese monopolio determinó también las naciones y las editoriales donde se adquirían los libros.

Finalmente, se puede hacer referencia a dos momentos históricos importantes en la historia de las bibliotecas novohispanas y luego mexicanas de diferentes corporaciones eclesiásticas. El primero es el relativo a las medidas adoptadas por la Corona española tras la expulsión de la Compañía de Jesús en 1767; una de esas disposiciones fue la relativa a trasladar las obras contenidas en las bibliotecas jesuitas a otras corporaciones, como los conventos o la Real Universidad de México, previa separación de los libros

30 Índice último de los libros prohibidos y mandados a expurga: para todos los reinos y señoríos del catolico rey de las Españas, el Señor don Carlos IV, 1790, p. 140.

31 Gómez, Navegar con libros. El comercio del libro entre España y Nueva España (17501820), p. 2011. 
prohibidos por la inquisición y la Corona española. ${ }^{32}$ En este sentido debe recordarse que las obras de Ignacio fueron prohibidas, por lo cual su destino fue incierto, pese a ello, algunos ejemplares lograron subsistir hasta nuestros días. Conjuntamente debe contemplarse que en varios colegios y casas jesuitas los libros permanecieron encerrados sin vigilancia alguna por largo tiempo antes de realizarse los inventarios, lo que pudo llevar a la perdida irremediable de ejemplares. Como ejemplo del retraso en los inventarios se cita el caso del noviciado de Tepotzotlán, cuyo inventario se inició cuatro años después del extrañamiento de los ignacianos.

El siguiente factor histórico a destacar, aunque pudieron existir otros, es el relacionado con la Ley de Nacionalización de Bienes Eclesiásticos expedida el 12 de julio de 1859 por el gobierno interino del presidente Benito Juárez. Debido a lo asentado en el artículo 12 de la ley, las bibliotecas de las corporaciones religiosas, a donde habían ido a parar ejemplares de las bibliotecas jesuitas, quedaron en manos del Estado depositándose posteriormente en museos, establecimientos públicos y bibliotecas, siendo una de las más importantes la Biblioteca Nacional de México fundada apenas dos años antes. ${ }^{33}$

\section{LOS EJEMPLARES DEL LIBRO EJERCICIOS ESPIRITUALES EN LAS}

\section{BIBLIOTECAS MEXICANAS}

Tras la revisión en los catálogos de las bibliotecas de la República Mexicana se encontraron 20 ejemplares del libro del santo distribuidos de la siguiente manera:

1. Biblioteca Francisco Xavier Clavijero de la Universidad Iberoamericana, campus México: cinco ejemplares

2. Fondo de origen resguardado en el Fondo Reservado de la Biblioteca Nacional de México de la UNAM: cinco ejemplares

3. Fondo antiguo de la Biblioteca Central de la UnAM: dos ejemplares

4. Biblioteca de la Universidad de las Américas, campus México: dos ejemplares

5. Biblioteca Pública del Estado de Jalisco: dos ejemplares

32 El traspaso se realizó atendiendo al artículo XXIX de la real cédula de 1768, la cual señala "que en las librerías de los colegios se haga separación de los libros morales y teológicos [...] que contengan doctrinas laxas y peligrosas y que estas se aparten del uso común [...] y los demás se aplicaran a seminarios, universidades, colegios y otros estudios." Colección general de providencias hasta aqui tomadas por el gobierno sobre el extrañamiento y ocupación de temporalidades de los regulares de la compañia que existían en los dominios de S.M. de España, Indias e irlas Filipinas a conseqüencia del real decreto de 27 de febrero y pragmática sanción de 2 de abril de este año. Parte II, 1769, p. 115.

33 González, 150 años de las Leyes de Reforma, 1859-2009, 2009, pp. 11-18. 
6. Biblioteca Miguel Lerdo de Tejada de la ciudad de México: un ejemplar

7. Biblioteca histórica José María Lafragua de la Benemérita Universidad Autónoma de Puebla: un ejemplar

8. Fondo antiguo José Gutiérrez Casillas S.J. localizado en la Biblioteca Eusebio F. Kino, de la Provincia Mexicana de la Compañía de Jesús: un ejemplar.

9. Capilla Alfonsina de la Biblioteca de la Universidad Autónoma de Nuevo León: un ejemplar

Por principio de cuentas debe indicarse que de las obras resguardadas en las mencionadas bibliotecas 11 corresponden al idioma latino y nueve al castellano. Como señala la historiografía, la edición príncipe del texto ignaciano —Vulgata de 1548 - se plasmó únicamente con el título, es decir, sin el nombre de Ignacio, mientras que las 20 ediciones ubicadas en los repositorios mexicanos incluyen el nombre del autor precedido siete veces por las siglas B. P. y 6 por las siglas S. P., las restantes sólo llevan el nombre del santo. En cinco además se agrega un título más amplio como el siguiente: cum versione literali ex autoprapho hispanico. En cuanto al formato, los ejemplares fueron impresos en $4^{\circ}, 8^{\circ}$ y $16^{\circ}$ y dos del siglo XIX en 16 y 20 centímetros.

En dos ocasiones el libro de los ejercicios fue encuadernado junto con otros textos que varían entre uno y tres; se trata del Directorio de los ejercicios espirituales, ${ }^{34} \mathrm{de}$ dos Instrucciones para los superiores y de la Industria para los mismos del General Claudio Acquaviva. Cada libro fue editado por separado y después se llevó a cabo la encuadernación con otros textos, entre uno y otro se dejaban cuatro hojas, el escrito nuevo comenzaba siempre con la portada elegida al imprimirse por separado. Probablemente se pensó que sería mejor encuadernar varios libros para que los directores tuvieran en un mismo tomo todos los escritos necesarios para dar los ejercicios..$^{35}$

34 El jesuita Miguel Lop Sebastiá, señala que las normas prácticas, los consejos y los avisos relativos a la manera de dar los ejercicios es lo que recibió el nombre de Directorio. Como sucedió con el texto de la Vulgata, la confección del Directorio pasó por diferentes etapas y por diferentes autores, siendo el primer autor el propio Ignacio. También escribieron diversos consejos y comentarios otros ejercitantes como Jerónimo Nadal o Juan Jerónimo Domenéch. Durante el generalato de Everardo Mercuriano se hizo el primer intento de elaboración de un directorio oficial, componiendo el mismo un directorio, además de solicitar a Diego Miró y a Polanco redactar sus directorios (el de Miró alcanzó gran difusión), pese a los esfuerzos de Mercuriano, el directorio oficial se confeccionó en el generalato de Claudio Aquaviva. La versión provisional quedó lista en 1591, se imprimió y fue remitida a toda la Compañía con la intención de que se enviaran comentarios, pero fueron muy pocos, por esa razón, en 1593 Aquaviva designó una comisión presidida por Gil González, quien dio su aprobación a las observaciones remitidas, pero incomprensiblemente, indica Lop, el Directorio oficial se editó hasta 1599, culminando con ello, los trabajos relacionados con dicho escrito; en total se hicieron 43 versiones. Lop, Los directorios de ejercicios, 1540-1599, pp. 15-17.

35 En términos generales, el libro está dividido en 20 anotaciones, título, presupuesto, principio 
Todas las obras comienzan con los preliminares, en los ejemplares del siglo XV y hasta 1657, el preámbulo consta del Breve Pastoralis officci emitido por Paulo III en 1548, donde además de exaltar y recomendar los ejercicios narra el proceso de aprobación de la Vulgata. Después de 1657 se agregó el breve de Alejandro VII, en el cual se otorga indulgencia plenaria y remisión de todos los pecados a los jesuitas, a los miembros de otras órdenes regulares y a los seculares que realizaran en las casas de la Compañía de Jesús los ejercicios de ocho días.

Ya en el siglo XvIII se adjuntó el documento de la Congregación del Concilio autorizada por Clemente XII en 1732, en él se dispuso que los arzobispos, obispos y demás ordinarios de Italia, islas adyacentes y todos los reinos y dominios de España, fomentaran entre los curas, confesores, canónigos y demás beneficiarios dedicados al servicio del coro, la práctica de los ejercicios espirituales una vez al año durante 10 días en las casas de la orden o en otras moradas piadosas o regulares. Al igual que lo hizo Alejandro VII, Clemente también otorgó a los ejercitantes indulgencias a sus pecados; además los absolvió de la residencia durante los días que se acudiera a los ejercicios y mandó se les pagasen sus honorarios y emolumentos completos. Asimismo, señaló que antes de ser promovidos a las sagradas órdenes, los aspirantes efectuaran los ejercicios. Finalmente, el Papa dio permiso a la Reverenda Cámara Apostólica para editar el libro de Ignacio en castellano; el mismo privilegio fue otorgado a los ordinarios eclesiásticos (obispos y arzobispos). Lo dispuesto por el pontífice obedeció, según sus palabras, al ruego hecho por los obispos españoles, a los pasos dados por su antecesor y a su interés por preservar la disciplina eclesiástica.

En 1749, por ejemplo, el cura del sagrario de la catedral sevillana, Pedro Muñoz de Zárate solicitó autorización para reimprimir el libro publicado por la Cámara, la licencia fue otorgada por el obispo coadministrador de dicha iglesia en el mismo año, la impresión corrió a cargo de la imprenta De los Recientes.

El impreso más antiguo localizado en los repositorios mexicanos es Exercitia Spiritualia Ignatij de Loyola, Romae: In Collegio Societatis Iesu, 1596, perteneciente a la Biblioteca de Jalisco. Le siguen Exercitia Spiritualia B. P. Ignatii Loyolae, Romae: in Collegio Rom. Iesu Societat, $1606,16^{\circ}$, la portada presenta un frontispicio xilográfico con el retrato de incorporación del medallón de San Ignacio, se han encontrado cuatro, en la Biblioteca Central existen dos, en la Biblioteca Nacional uno y otro en la biblioteca de Jalisco.

La Biblioteca de la Universidad de Nuevo León resguarda Exercitia Spiritualia B. P. Ignatii Loyolae, Romae: Collegio Romano, 1616, $8^{\circ}$, con

y fundamento, exámenes particulares y generales para confesarse y general ordinario, meditaciones de los ejercicios entrelazados con notas, advertencias y reglas. Diccionario Histórico de la Compañía de Jesús, p. 1222. 
frontispicio xilográfico donde se incorpora el medallón de San Ignacio y el escudo de la Compañía de Jesús. El escudo está compuesto por un sol adornado con lenguas de fuego que representa la presencia y la fuerza de Dios en cada una de las misiones que la Iglesia encarga a los hijos de Ignacio, son diez llamas de fuego que recuerdan que Jesús es la luz del mundo. Al interior tiene el monograma o anagrama IHS, es decir, el nombre de Jesús en griego, y los tres clavos que han sido interpretados como los clavos de la crucifixión o como los votos de los novicios de la orden. ${ }^{36} \mathrm{Al}$ inicio de la obra se añade la oración que Íñigo solía repetir en sus ejercicios, esta oración anónima forma parte de los triples coloquios a partir de la segunda semana de los ejercicios. ${ }^{37}$

Del siglo XVII existen dos ejemplares más publicados ya por impresores ajenos al colegio, el primero es Exercitia spiritvalia S. P. Ignati Loyolae, Antverpiae: Apvd Ioannem Mevrs[iv]m 1635, $8^{\circ},{ }^{38}$ pertenece a la Biblioteca Nacional. Esta edición es una reimpresión de la romana, aunque el grabado de la portada difiere, en ella se muestra el busto del santo siendo coronado y en la parte baja del mismo se plasma un libro con el escudo de la orden. El segundo ubicado en la Biblioteca de la Universidad Iberoamericana es Exercitia spiritualia S.P. Ignatii Loyolae, fundatoris Ordinis Societates Jesv cum bullis pontificum, ium approbations exercitiorum; tum indulgentia plenarie, proomnibus, qui ocfiduo illis vacant in domibus ejusdem societatis: brevi infuper instructione meditandi quae omnia \& dilucidantur \& illustrantur pluribus exaere impreffis imaginibus, Antuerpiae: Apud Michaelem Knobbaert, $1689,8^{\circ}$, contiene grabados en cobre como el de la mano correspondiente a la parte dedicada a los exámenes de conciencia y una ilustración en el frontispicio del niño Dios con una cruz en el pesebre.

Un libro en latín y cuatro en castellano provienen del siglo XvIII, a saber, Exercitia spiritualia S.P. Ignatii Loyolae fundatoris Ordinis Societatis Iesu; cum Bullis Pontificum tum approbationis Exercitiorum tum indulgentia plenariae pro omnibus qui octiduo illis vacant in domibus ejusdem Societatis, brevi insuper instructione meditandi quae omnia \& dilucidantur et illustrantur pluribus ex aere impressis imaginibus, Belgium: Viduam Henrici Verdussen, $1733,8^{\circ}$, se localiza en la biblioteca José María Lafragua.

Los ejemplares castellanos son los siguientes: Exercicios espirituales, Ignatius de Loyola, Romae: Ex Typographia Reverendae Camerae Apostolicae,

36 Pfeiffer, "El emblema de la Compañía de Jesús", p. 13.

37 Alma de Cristo. Alma de Cristo, santifícame. Cuerpo de Cristo, sálvame. Sangre de Cristo, embriágame. Agua del costado de Cristo, lávame. Pasión de Cristo, confórtame. ¡Oh mi bien Jesús, óyeme! Dentro de tus llagas, escóndeme. No permitas que me aparte de Ti. Del maligno enemigo defiéndeme. En la hora de mi muerte, llámame. Y mándame ir a Ti. Para que con tus Santos te alabe. Por los siglos de los siglos. Amén. 
$1732,8^{\circ}$, resguardado en la Biblioteca Nacional. Dos ejemplares de Exercicios espirituales/B.P. Ignacio de Loyola, Sevilla: Imprenta de los Recientes, 1732 , $8^{\circ}$, se ubican en la Biblioteca de la Universidad de las Américas y, el tercero, en la Biblioteca Nacional. La portada tiene el escudo de la Compañía de Jesús, la edición cierra con el grabado de un querubín, por ser estos ángeles guardianes de la Gloria de Dios; los querubines aparecen constantemente en la iconografía jesuita. La edición es en realidad una reimpresión del libro publicado por la Reverenda Cámara Apostólica. Después del texto ignaciano aparecen las cartas escritas por Íñigo a los padres de los colegios de Coimbra y Portugal en 1547 y 1553 respectivamente, la carta dirigida a su confesor en Venecia, Manuel de Miona en 1536, asimismo, se anexa una carta dirigida a los lectores con la finalidad de incitarlos a realizar los ejercicios, así como noticias de otros autores que han escrito sobre los ejercicios y su autor. ${ }^{39}$

Exercicios Espirituales S. Ignacio de Loyola: con una introducción antes del texto del Santo, conveniente para formar el devido aprecio de estos exercicios y la idea de su método y practica, Valencia: Joseph Dolz, $1733,8^{\circ}$, tiene en la portada el escudo de la Sociedad de Jesús; se trata de una reimpresión de las ediciones de Amberes. La introducción fue redactada por el padre Jerónimo Julián, en ella, el jesuita incluye tres capítulos, en el primero da algunas noticias sobre el libro y explica su doctrina y método. En el segundo, habla sobre el aprecio y la autoridad que tienen los ejercicios en la Iglesia $^{40} \mathrm{y}$, en el último, presenta una breve explicación para meditar, recogida de diferentes partes del libro de Ignacio. El grabado de la portada corresponde al escudo de la Sociedad de Jesús. También forma parte de la colección de la Biblioteca Nacional.

Para cerrar la descripción de los ejemplares se hace mención de los libros publicados en el siglo XIX, uno está escrito en castellano y 3 en latín, todos forman parte de la estantería de la Universidad Iberoamericana. Los ejemplares son los siguientes: Exercicios espirituales de San Ignacio de Loyola, Madrid: Imprenta de la Real Compañía, 1800, 8 , S.P. Ignatii Loiolae Exercitia spiritualia: texto hispano ex diligenti, cum autograpo collatione restituto, Romae: Apud Salviucci, 1837, 16º se trata de una reimpresión de

39 La carta de apenas tres párrafos "contiene el panegírico más grande que conocemos hiciera San Ignacio de sus ejercicios". El escrito tuvo como finalidad solicitar a Miona practicar los ejercicios durante un mes y después de haberlo hecho, escribirle para saber si le había gustado, si no fuere el caso, Ignacio le pedía no contestarle. Obras de Ignacio de Loyola, pp. 668-669.

40 Para la composición de este capítulo, el padre señala que se valió del libro de los Ejercicios Espirituales, del Directorio, de historiadores de la orden —Francisco Sachino, Nicolás Orlandino y José Juvencio- , de algunos libros de Santa Teresa y San Francisco de Sales, además de lo escrito por Francisco Arias en su obra Del aprovechamiento espiritual y de los Opúsculos espirituales de Nicolás Lancicio. 
la obra en latín de Juan Roothaan estampada en la misma editorial dos años antes. Excercitia spiritualia S. P. Ignatti de Loyola: cum versione literali exautographo hispano; notis illustrata, Romae: escudebat Alexander Monaldi, 1738 y Exercitia spiritualia S. P. Ignatii Loyolae: cum versione literali ex autographo hispánico, Namurci: E. Typographia e douxfils, Bibliopolae, 1841, $16^{\circ}$, es una reedición de la obra publicada en 1837. En los preliminares, además de los documentos señalados con anterioridad, se anexa la carta escrita por Roothaan a todos los hijos de Loyola, la cual versa sobre el estudio y el uso de los ejercicios espirituales por ser considerados piedra angular en la formación de los jesuitas; la portada presenta el escudo de la orden.

Como se ha podido apreciar, a través de los libros localizados en los acervos mexicanos, así como mediante la consulta de los catálogos de bibliotecas y de repositorios bibliográficos extranjeros, en la Nueva España y en la República Mexicana no se hicieron ediciones o reimpresiones de los ejercicios ignacianos. Se desconoce por el momento si la Provincia Mexicana de la Compañía de Jesús solicitó licencia para imprimir la obra como sucedió en Perú, Castilla, Andalucía o Anteoquía, las peticiones fueron rechazadas por el padre Claudio Aquaviva en 1595, argumentando que los ejercicios estaban escritos para los directores y no para el ejercitante, además de señalar que Roma siempre había negado a las Congregaciones Provinciales la impresión del texto original castellano ${ }^{41}$ así pues, las provincias debieron esperar, ya que como se ha descrito, la primera edición castellana apareció en 1615 y hasta el siglo XVIII la Compañía de Jesús guardó para sí el privilegio de su edición.

\section{Derivaciones de los EJercicios Espirituales de San Ignacio}

El Diccionario histórico de la Compañía de Jesús señala que cuando el impreso ignaciano llegó al colegio de Gandía en 1548, la abadesa de las clarisas y su tío comenzaron a utilizarlo para la meditación diaria, fue en este momento cuando empezaron a surgir las llamadas derivaciones apostólicas. Un tipo de derivación es la relacionada con las obras escritas, pueden dividirse en dos grandes grupos: los libros de meditaciones y los adaptados o comentados. ${ }^{42}$

El otro tipo de derivación tiene que ver con el número de días en que se daban los ejercicios y con el tipo de ejercitantes. Ignacio formuló sus ejercicios para ser dados y tomados en retiro de cuatro semanas de manera particular, y orientados a la elección de estado o elección para reformar la vida ${ }^{43}$ No

\footnotetext{
41 Calveras, "Los textos latinos de los ejercicios anteriores a la vulgata", p. 5.

$42 \quad$ Diccionario Histórico de la Compañía de Jesús, p. 1229.

43 La elección es el propósito y el fin hacia el que van dirigidos los ejercicios. El proceso de elección es el momento de los ejercicios cuando el ejercitante trata de descubrir y decidirse
} 
obstante, su autor validó las variaciones en la duración, los más usuales eran de 8 o 10 días conocidos como tandas. Esta muda dependió de a quién estaban dirigidos los ejercicios: ignacianos, novicios, clérigos regulares, colegiales jesuitas, monjas, público en general, congregaciones marianas, misiones populares, entre otros. Las derivaciones apostólicas estuvieron íntimamente ligadas entre sí.

En este apartado no se hará una descripción pormenorizada de los autores y sus textos, pues existen 116 ejemplares correspondientes a 18 jesuitas en las bibliotecas de la UNAM, así como en la Biblioteca de la Universidad Iberoamericana - en otro momento de la investigación deberán consignarse los ejemplares de las otras bibliotecas consultadas. Por lo tanto, únicamente me detuve en algunos autores basándome en aquellos cuyas obras tuvieron mayor difusión en México, dando noticias generales de los otros.

\section{LIBROS DE MEDITACIONES Y LIBROS ADAPTADOS O COMENTADOS}

Los libros de meditaciones tuvieron como finalidad ayudar a los fieles en la reflexión diaria o en los días de retiro. En ellos, el proceso ignaciano sólo formaba la trama interna, es decir, quedaba muy diluido. ${ }^{44}$ No obstante, las obras de meditaciones eran muy significativas, pues incitaban a la imitación y al seguimiento de Cristo. ${ }^{45}$ Entre los escritores de meditaciones más famosos

por lo que Dios quiere de él, en cuanto a la orientación de su vida. Dicha cuestión está ya de alguna forma comunicada en el mismo título de los ejercicios que se ofrecen para averiguar y encontrar la voluntad divina en la disposición de la propia vida. Vargas, "La anotación 15a. de los Ejercicios Espirituales de San Ignacio. La rectitud de la intención del que da los ejercicios y su interpretación en algunos comentarios clásicos", p. 50. Para ayudar a los ejercitantes a comprender y aclarar aspectos relacionados con los pasos a seguir para llegar a esta elección, así como para ayudar a los acompañantes, el jesuita Giuliani escribió, La experiencia de los ejercicios espirituales en la vida, 1992. Iparraguirre, Historia de la práctica de los Ejercicios Espirituales de San Ignacio de Loyola. Volumen I, p. 126.

45 En el siglo XVI, la oración ignaciana fue objeto de dos tendencias predominantes: la afectivoactiva y la afectivo-contemplativa. Lo afectivo se refiere al diálogo con el Señor al que se ha consagrado la vida. En la tendencia activa la oración se efectuaba a través de la lucha constante para la salvación de las almas, mientras que la tendencia contemplativa buscaba el recogimiento. Estas posturas llevaron a una serie de disputas entre sus partidarios (1550 y 1565), lo que llevó a que entre 1565 y 1570 se buscara sistematizar un método de oración, en esta búsqueda triunfó la vía afectivo-activa, pues era la que representaba las enseñanzas dejadas por Ignacio, no obstante, se permitió en casos especiales, realizar la oración en retiro. A lo largo de estas pugnas en torno al problema de la oración, se trata también sobre la meditación y la contemplación, la primera es concebida como el medio más poderoso para asimilar las verdades "que encarnadas en el alma del apóstol daban vigor y fuerza al ministerio" y, la segunda como un medio para la vida apostólica. En los intentos hechos para sistematizar la oración se prestó gran atención a la preparación de la meditación, y 
se encuentra el jesuita vallisoletano Luis de la Puente. En sus obras, el autor explica diversas partes de la meditación

[...] señalando con gran sentido práctico y flexibilidad el modo con que debe emplearse el ejercitante. Indica una gran variedad de métodos, equilibra la enseñanza con la acción de la gracia. Tiene en cuenta diversos estados y situaciones de cada persona, soluciona las principales dificultades. Insiste en que la "esencia" consiste en "hablar" dentro de nosotros mismos con Dios Nuestro Señor". 46

En las bibliotecas de la UNAM se encontraron un total de 10 ejemplares de Luis de la Puente, divididos en cinco obras, Meditaciones espirituales... ${ }^{47}$ (tres), Compendio de las meditaciones... ${ }^{48}$ (dos), Meditaciones de los ministerios de nuestra sacta fe... ${ }^{49}$ (dos), Sentimientos y avisos espirituales... ${ }^{50}$ (dos) y Meditaciones espirituales para los días de cuaresma..${ }^{51}$ (uno). La mayoría de las obras se publicaron en España, a saber, cinco en Madrid, una en Barcelona y otra en Valladolid; las ciudades de Amberes y Londres también contribuyeron con un ejemplar.

Respecto a las obras comentadas, explanadas o adaptadas, aunque se consideraban incompletas por fijar su atención sobre algún aspecto de los ejercicios o contener glosas o ampliaciones, su difusión y publicación fue extensa. A través de ellas sus autores intentaban explicar y penetrar la doctrina de los ejercicios; varios de ellos, no satisfechos, con simplemente discutir el método, se ocuparon también de la práctica.

En la Biblioteca Nacional de México y en la biblioteca Eusebio F. Kino se localizaron textos elaborados por 18 jesuitas, de 14 se conservan entre

poca relevancia a la materia sobre la cual se meditaba, ya que lo trascendente era el modo. Iparraguirre, "La oración en la Compañía naciente" pp. 467-486. Iparraguirre, "El P. Luis de la Puente maestro de oración", pp. 227-252.

47 ...del P. Luis de la Puente. La edición carece de portada, sólo se sabe que corresponde al siglo XVII. Otra editada en Madrid, en la imprenta de Antonio Pérez de Soto en 1751 y la última en Barcelona por la imprenta de María Ángeles Martín viuda, 1757.

48 ...repartidas por todas las domicas del año de las quatro postrimerías y beneficios divinos por los días de la semana, Madrid por don Pedro Joseph Alonso y Padilla, 1709. La otra en latín, editada en Amberes por la tipografía de Philiberti Chabanne, ad Forum Franciscanorum, 1713.

$49 \quad$...con la práctica de la oración metal sobre ellos, Valladolid, Juan Godínez de Millis, 1607. La otra publicada en Madrid por Melchor Sánchez a costa de Gabriel de León, 1655.

50 ...del venerable Padre Luis de la Puente, Amberes, Baltazar Moreto, 1672. La otra se publicó en Madrid por Antonio Pérez Soto en 1753.

51 ...de las obras del venerable Padre Luis de la Puente de la Compañia de Jesús, Madrid, Oficina de Antonio Pérez de Soto, 1753. 
uno y ocho ejemplares, ${ }^{52}$ mientras que de cuatro se custodian entre nueve y 12. Los 14 primeros autores están representados por jesuitas de diferentes nacionalidades: franceses, alemanes, italianos, españoles, incluso hay un mexicano. Todos escribieron durante el Antiguo Régimen, en su idioma natal y fueron traducidos al castellano en diversas ocasiones.

La mayoría de las obras conservadas en México procedían de las imprentas españolas, destacando las editadas en Madrid, aunque también encontramos, en número muy reducido, libros procedentes de Barcelona, Salamanca, Sevilla, Valladolid y Valencia; otros fueron impresos en Lyon y Venecia durante los siglos XVII y XVIII, y uno se editó en el siglo XIX en Londres. En la ciudad de México también se hicieron ediciones, que por cierto, le siguieron en número a las madrileñas; se publicaron tanto en la época colonial, especialmente en el setecientos y en la centuria decimonónica; la ciudad de Puebla que tenía permiso para imprimir aportó un libro.

El contenido de los textos, como se ha indicado, se acercaba a uno o varios aspectos relacionados con los ejercicios espirituales, así por ejemplo, Simons Bagnati daba premisas para santificar la muerte siguiendo las máximas de los ejercicios, José María Genovese se centraba en las lecciones espirituales, Daniel Pawloswki en la forma como Dios hablaba al corazón de los religiosos ejercitantes y el mexicano Antonio Núñez de Miranda, quien era confesor de Sor Juana, fijó la atención en la contemplación, la oración y la meditación sobre la vida de Cristo con la finalidad de acercar a las religiosas a la práctica de los ejercicios ignacianos. La obra tiene que ver más con la práctica mística que con el ascetismo. ${ }^{53}$

Llegamos por último al grupo compuesto por cuatro jesuitas con el mayor número de obras localizadas; ellos son los italianos Carlo Gregorio Rosignoli con 11, Sebastián Izquierdo con 11, Carlo Ambrosio de Cataneo con 10, al igual que el francés Francisco Nepueu. De Cataneo ubicamos 3 libros, Esercizj Spirituali di S. Ignazio/opera opustuma del Padre Carl' Ambrogio Cattaneo, Venezia: Presso Niccolò Pezzana, 1744, 4 , Exercicios Espirituales de S. Ignacio, obra posthuma, escrita en italiano por el P. Carlos Ambrosio Cataneo, de la Compañia de Jesus, y traducida al español por el P. Pedro Lozano, de la misma Compañía, Madrid: En la imprenta de D. Gabriel Ramirez, y à su costa, $1754,8^{\circ} .{ }^{54}$ La obra está compuesta por meditaciones, reflexiones, reglas,

52 Los jesuitas localizados son los siguientes: Simons Bagnati, Louis Bourdelau, Ignace Diertins, Camillo Ettori, José María Genovese, Francisco Xavier Idiáquez, Tobias Lohner, Antonio Núñez de Miranda, Paolo Segneri, Tomás Turrubia, Francisco Salazar, Juan Loyola, Daniel Pawlowski y Jacques Nouët.

53 Rubial, "Reseña del libro. El discurso de la espiritualidad dirigida: Antonio Núñez de Miranda, Confesor de sor Juana", p. 243.

54 Se reimprimieron por la misma imprenta en 1766 y 1788. 
un breve método para la confesión y exámenes generales, particulares o sobre algún punto en específico. Ignacio Iparraguirre señala que tal escrito estuvo en boga durante el siglo XVIII por tener una forma académica, llena de imágenes y figuras retóricas; en él, su autor dialoga con el ejercitante..$^{55}$ Otra obra del autor es Maximas eternas: propuestas en lecciones, para quien se retira à los exercicios Espirituales De San Ignacio. Obra posthuma cescrita en italiano por el P. Carlos Ambrosio Cataneo, De la Compañia De Jesus, y traducida al español por el Padre Pedro Lozano, De la misma Compañia, Madrid: en la imprenta De D. Gabrièl Ramirez, y à su costa, 1754, $8^{\circ}$. Cataneo da lecciones espirituales para ocho días sobre el pecado, la muerte, el juicio, el infierno entre otros temas. La obra fue reimpresa por el mismo editor en 1764, 1766, 1776 y 1788, y una vez, se imprimió en Venecia en 1746.

Carlo Gregorio Rosignoli publicó Verdades eternas: explicadas en lecciones, ordenadas principalmente para los dias de los ejercicios espirituales por el P. Carlos Gregorio Rosignoli; tr. del toscano por un religioso de la misma Compañía, Sevilla: por Juan de la Puerta, $1714 .{ }^{56}$ En la introducción de la obra dirigida al lector, el jesuita dice que "han salido a la luz varias meditaciones, pero que faltaban algunas lecciones ajustadas a las meditaciones que sirviesen de imprimir más vivamente en el ánimo aquellas máximas eternas de los ejercicios espirituales, pues son la lección y la meditación las dos alas de la paloma que levantan al cielo". ${ }^{57}$ Contiene 16 lecciones, correspondientes a 15 días de ejercicios, así como meditaciones para cada día del mes, reglas para vivir santamente, un método para prepararse para la oración mental, examen de la conciencia, etcétera. A nueve ediciones se le agregaron meditaciones breves sobre los novísimos - muertes, juicio, purgatorio, cielo e infierno-, repartidas en los días del mes.

Francisco Nepueu, escribió Pensamientos o reflexiones cristianas para todos los días del año, escritos por el R. P. Francisco Nepveo, Amberes: a costa de los hermanos Tourner, $1744 .{ }^{58}$ El libro contiene reflexiones para la vida espiritual, los novísimos, las virtudes, penitencia, misa, comunión, culpa,

55 Iparraguirre, Orientaciones bibliográficas sobre San Ignacio de Loyola, p. 52.

56 La obra se reimprimió ocho veces: Madrid: Gabriel Ramírez, 1764; Madrid, Andrés Ortega, 1764: Madrid: oficina de Manuel Martínez, 1777; Londres, R. Ackerman, Strand, 1829; México: Imprenta de Abadiano y Valdés, 1843; México: Filadelfia: Compañía Estereotipográfica de la América, 1847; México: Garnier Hnos, 1856 y México: imprenta de M. Munguía, 1858.

57 Rosignoli, Verdades eternas explicadas en lecciones ordenadas principalmente para los dias de Exercicios Espirituales, p. III.

58 Otras ediciones en Amberes: a costa de los hermanos de Tourner, 1753; Barcelona: imprenta de Jayme Osset, 1764; Barcelona: imprenta de Maria Angeles Marti, 1766; Madrid: Real Compañía de Impresores y libreros, 1779 y 1781-1782. Se sabe que la primera impresión se efectuó en Lyon en 1700, pero no se ha podido localizar. 
misterios de la vida de Jesucristo, etcétera, siguiendo el método ignaciano como él mismo lo indica. Otros libros de este autor fueron Método de oración mental y su práctica, Madrid, 1761 y Retiro espiritual según el espíritu y método de San Ignacio, traducida del francés al italiano y estampada en Venecia en 1721.

El autor preferido por los impresores mexicanos fue Sebastián Izquierdo, el privilegio para imprimir la obra fue otorgado por primera vez a Diego Fernández de León en el siglo XVII. Izquierdo escribió Practica de los exercicios Espirituales por nuestro padre San Ignacio por Sebastián Izquierdo de la Compañia de Jesus. Roma: por el Varense, 1675. ${ }^{59}$ La clave del éxito de dicho autor se debió a su eminente practicidad, solidez y claridad, ya que ofrece una verdadera guía ilustrada de los ejercicios espirituales de San Ignacio, pero reducidos a ocho días. Doce de las 14 láminas grabadas se realizaron a partir de las monumentales Evangelicae Historiae Imagines (1593) de Jerónimo Nadal. Las imágenes no son sólo descripciones, sino dispositivos mnemotécnicos que permiten al lector de nuestro siglo mirar "preciosos ejemplos de imágenes que inspiran a la meditación, dirigen la recepción de las enseñanzas y las hunde en la memoria". Específicamente son memorables las imágenes del infierno y del abismo, donde se muestran las intenciones pedagógicas y las posibilidades del libro. ${ }^{60}$ Así pues, se trata también de un libro de emblemas cuya finalidad era la de poder llevar a cabo los ejercicios sin la guía de un director. ${ }^{61}$

Hasta el momento se ha dado cuenta de los ejemplares de los Ejercicios Espirituales de San Ignacio de Loyola resguardados en las bibliotecas mexicanas, además de haberse hecho alusión a otros jesuitas que escribieron libros de meditaciones u obras adaptadas o acomodadas. Para concluir con el análisis aún hace falta conocer a quién pertenecieron los ejemplares antes de llegar a su destino actual y acercarnos a los ejercitantes.

Puebla: Diego Fernández de León, 1685: México: Imprenta Nueva de la Biblioteca Mexicana, 1756; Roma: por Marti, 1724; México: por la viuda de Miguel Rivera, 1709; Sevilla: en la imprenta Real de la viuda de Diego Lopez de Haro, 1754; México: Imprenta de los herederos del licenciado Joseph Jaregui, impresa en 1782, 1783; México: Bernardo de Hogal, 1797; México: reimpresa en México en la oficina de María Fernández de Jauregui, 1808; México: Luis Abadiano y Váldés, 1838.

60 Gray, "Praxis Exercitiorum Spiritualium P.S.N. Ignatti" jamesgray2.wordpress.com.praxisexercitiorum-spiritualium-p-s-n-ignatti [consulta el 30 de enero de 2020].

${ }_{61}$ El libro de emblemas es un género poético-pictórico con intención moralizante, la obra se revela como un vehículo útil de formato para obras como los libros infantiles, los devocionarios, los manuales de meditación, etcétera. La emblemática se convirtió en una corriente artística y literaria en el siglo XVII, con la cual se identificaron los jesuitas "dándose cuenta de su potencial innovador como arma de combate contra la herejía protestante, como texto de estudio, como vehículo para enaltecer a Dios, como formato para su sistema de oración, y finalmente como medio para dar a conocer la historia y los ideales de la Orden". Campa, "La génesis del libro de emblemas jesuita" 1996, pp. 43-44. 


\section{INSTITUCIONES DE ORIGEN DE LAS OBRAS Y SUS EJERCITANTES}

Mediante las marcas de fuego, ex libris y sellos de goma es posible saber a qué corporaciones o personas perteneció el libro de los ejercicios. ${ }^{62} \mathrm{La}$ obra editada en 1596 formaba parte de la biblioteca del Convento franciscano de Nuestra Señora de Zapopan en el estado actual de Jalisco. Las ediciones de 1606 pertenecieron al colegio de San Ildefonso de México, a la Congregación de la Buena Muerte auspiciada por los jesuitas, al convento de Zapopan, y de otra no se tiene ninguna noticia, ya que a veces los libros no contenían marcas de fuego, sellos o ex libris.

La de 1616 fue del rector de un colegio de Puebla y posteriormente fue a parar a manos del bibliófilo mexicano Emeterio Valverde Téllez; la de 1735 estaba en la librería del Convento de San Agustín; la de 1675 en el Colegio de San Fernando de los misioneros de la orden de San Francisco de Propaganda Fide. Finalmente, el libro editado en 1689 era de Gloria Rasmussen, ex alumna de la Universidad Iberoamericana, y se desconoce cómo llegó a sus manos.

Los ejemplares del siglo XVIII se distribuyeron de la siguiente forma: 1733, Colegio del Estado de Puebla, donado por el presbítero Pedro N. Blanco y el segundo de ese año estaba en el Colegio Apostólico de Propaganda Fide de San Fernando, en el libro se encuentra un ex libris manuscrito que dice lo siguiente "de Franco. Teresa". No se sabe si el volumen fue pedido a los libreros de la ciudad para que lo trajeran de Europa o si había pertenecido a otro establecimiento franciscano o jesuita, ya que no existe ninguna marca de procedencia o tenencia.

El libro editado por la Cámara Apostólica era del convento de San Diego y las publicaciones de 1749 hechas por la imprenta De los Recientes formaron parte de la Biblioteca Turriana de la Catedral Metropolitana de México y del Convento de San Juan de la misma ciudad, además de contener una de ellas un ex libris manuscrito donde se indica que perteneció a María Antonia de San Ignacio, quien suplica que si alguien lo encuentra se lo devuelva "por amor De Di". Finalmente, este ejemplar tiene dos sellos de tinta, en el primero dice De ex libris Historia México Colegio Máximo S.I., y, el segundo, "De la Asociación Histórica Americanista".

La obra de 1800 tiene un sello con la leyenda Colegio de San Francisco Javier de Tepotzotlán. Esta institución había sido el noviciado de los jesuitas, pero a partir de 1776 el edificio albergó el Colegio Seminario para instrucción,

62 "En lo que corresponde a las marcas de fuego asociadas a los jesuitas, se sabe que son muy pocas las que se conservan al confrontar la evidencia con los datos que se conocen de sus establecimientos. Tal condición permite inferir que a partir de la expulsión podrían haberse eliminado de forma sistemática las evidencias de la procedencia jesuita". García, "Entre el olvido y la supervivencia: Los libros jesuitas del colegio de San Luis Potosí”, p. 55. 
retiro voluntario y corrección de clérigos seculares fundado por el arzobispo ilustrado Alonso Núñez de Haro. En este recinto los clérigos residentes, los candidatos al sacerdocio, los curas y otros eclesiásticos realizaban ejercicios espirituales una vez al año, empleando los directores el texto El eclesiástico instruido en los principales ministerios y obligaciones de su estado compuesto por el arcediano de Ecija, Tomás Ortiz de Garay, teniendo presentes los diez días de ejercicios de San Ignacio; la oración se tendría por las novísimas, la pasión y la muerte de Jesucristo. ${ }^{63}$

La utilización de esta obra, en lugar de la del santo, se debió a los ya explicado sobre la prohibición del libro de Ignacio, no obstante, varios impresores españoles continuaron editándolos como una respuesta al antijesuitismo. Aunque también pudo deberse a que el prelado se decidió por el otro autor, pues su obra estaba dirigida a los clérigos seculares.

Por último, tenemos los ejemplares editados en 1837 y 1841 , es decir, después de la segunda supresión de la Compañía de Jesús en 1821; éstos llevan un sello con la leyenda "Residentia Angelorum S.I. Mexici, IHS".

En resumen, durante la época colonial sólo se sabe que dos ejemplares de los libros localizados en las bibliotecas mexicanas pertenecieron a un colegio jesuita y otro a una congregación ligada a la orden, sin embargo, esta afirmación debe tomarse con reservas, ya que se desconoce la procedencia de algunos libros, además de que varios no cuentan con ninguna marca para su identificación. De los libros pertenecientes a la biblioteca de la catedral y de los provenientes de las estanterías de los conventos de las órdenes religiosas puede aducirse que su existencia no es extraña, pues como se ha indicado, los papas impulsaron la realización de los ejercicios de San Ignacio precisamente a los miembros de esos cuerpos, además de tomar en cuenta los traslados de libros ocurridos después de la expulsión y del decreto de nacionalización de bienes eclesiásticos. En el México republicano dos ejemplares regresaron a la Compañía de Jesús y otros quedaron en manos de los franciscanos.

Los ejercitantes, por tanto, fueron jesuitas, colegiales ignacianos, congregantes, clérigos seculares, clérigos regulares, laicos, indígenas, mujeres y religiosas como habían dispuesto los papas, además de que San Ignacio y sus compañeros dieron ejercicios a personas no pertenecientes a la orden. En el caso de las mujeres se sabe que las colegialas del Colegio de San Ignacio de las Vizcaínas realizaban periódicamente los ejercicios del santo vasco. Ello se debió a que dicho colegio se basó en la premisa ignaciana, "a la mayor gloria 
de Dios", con la intención de "mostrar que las mujeres que en él se educaban darían Gloria a Dios con sus vidas". ${ }^{64}$

Respecto a las obras escritas por otros jesuitas debemos preguntarnos si éstas formaron parte de las mismas estanterías. Con relación a los autores de los cuales se dieron noticias en el apartado anterior, se sabe que sus libros fueron adquiridos por conventos masculinos y femeninos de mercedarios, dieguinos, franciscanos y monjas agustinas recoletas. También estuvieron en las bibliotecas de las residencias jesuitas de Guadalajara y Puebla, de los colegios Máximo de San Pedro y San Pablo y de San Ildefonso de la ciudad de México, los colegios de la Merced, San Fernando, Vizcaínas, además de la biblioteca de la catedral metropolitana y de la biblioteca de la Casa Profesa, la cual fue entregada a los oratorianos de San Felipe Neri después del extrañamiento de los ignacianos.

Como sucedió con el libro de Ignacio, varios ejemplares pasaron por diversas instituciones a lo largo del tiempo. La edición de 1727 de Retiro espiritual para el uso de comunidades religiosas, del francés Bourdelau, fue primero del colegio de San Ildefonso, luego de los oratorianos, posteriormente se integró a la biblioteca del colegio de San Fernando y, finalmente, quedó en manos de fray Tomás de Paniagua, pero usado por el padre Castro. La obra se resguarda en la Biblioteca de la Universidad Iberoamericana.

Los libros de meditaciones de Luis de la Puente pertenecieron a las librerías del Oratorio de San Felipe Neri, del Colegio de San Juan de Letrán y de los conventos de San Cosme, San Francisco y San Diego. Así pues, sus meditaciones fueron de interés para clérigos regulares ya contemplados - dieguinos y franciscanos - y para nuevos ejercitantes como los seculares y seglares oratorianos que se establecieron en la ciudad de México en 1661. La inclusión de esos textos en su biblioteca se debió a que San Felipe Neri, fundador de los filipenses, admiraba el modo de orar de Ignacio y tenía en alto concepto sus ejercicios espirituales. Los textos de Puente, localizados en la biblioteca Eusebio Dávalos Huerta del INAH, cubrían también un público más amplio, el de los mestizos, indios y criollos del colegio de Letrán.

Los receptores de los ejemplares de los cuatro autores que se destacaron difundieron la espiritualidad ignaciana a nuevas comunidades. Carlo Ambrosio de Cataneo figuró en las librerías de los agustinos y carmelitas, además de otros actores ya conocidos, franciscanos, jesuitas y colegialas de San Ignacio de las Vizcaínas, ${ }^{65}$ mientras que la de Carlos Gregorio Rosignoli reafirmó la presencia de los ejercicios en el convento de San Diego, el colegio de San Fernando y nuevamente en Vizcaínas. Francisco Nepueu fue localizado en los conventos de San Sebastián y San Joaquín de Tacuba de los carmelitas descalzos y en

64 Muriel, Los vascos en México y su colegio de las Vizcaínas, p. 26.

65 Ejemplar perteneciente a la biblioteca de la Universidad Iberoamericana. 
el Convento Grande de San Francisco. Sus libros además contienen ex libris que permiten conocer a qué personajes pertenecían, basta un ejemplo relativo al libro Pensamientos, el cual era de fray Antonio Larcos del Colegio de San Fernando. Finalmente, la obra de Sebastián Izquierdo formó parte de las bibliotecas del colegio Máximo de San Pedro y San Pablo, del Oratorio de San Felipe Neri y de los colegios de San Fernando y Vizcaínas.

\section{REFLEXIONES FINALES}

Al revisar los diferentes acervos bibliográficos de la ciudad de México se puede advertir la importancia del libro de los ejercicios espirituales en la vida de los miembros de las instituciones novohispanas y mexicanas que no pertenecían a la Compañía de Jesús. Esa relevancia las llevó a hacerse de ejemplares que les permitieran conocer y practicar los ejercicios como parte de sus tareas espirituales. El empeño de hombres y mujeres pertenecientes a esos cuerpos no cesó con la expulsión de los regulares de Loyola en 1767 ni con la llegada del régimen republicano a México, el cual tenía entre una de sus consignas secularizar y modernizar la cultura, así como la educación eliminando ambos aspectos del yugo de los religiosos.

La consulta de las bibliotecas mexicanas permite observar una aparente difusión de la Vulgata y el Autógrafo, aunque como se vio a lo largo del texto, el reducido número de ejemplares pudo deberse a diferentes factores ya apuntados. Por ello, en el devenir de la investigación propuesta será necesario acercarse a los inventarios de las bibliotecas novohispanas o a los trabajos ya efectuados sobre el tema. Asimismo, deberá recurrirse a las fuentes empleadas por los investigadores dedicados al estudio de la circulación del libro, de los impresores y de las imprentas.

La indagación también nos acercó a los jesuitas que siguiendo el espíritu de los ejercicios de Íñigo redactaron obras sobre determinados temas que les resultaban de interés. Además, acomodaron sus escritos a diferentes periodicidades que van desde ocho días hasta un año y a diferentes tipos de ejercitantes tanto masculinos como femeninos. Finalmente podemos decir que para convertir sus libros en obras prácticas varios de esos autores incluyeron imágenes que explicaban visualmente algún tema y las acompañaban de un texto que ahondaba en el mensaje a transmitir.

El estudio también demostró la necesidad de examinar más de cerca o de construir un sistema propio para presentar los impresos, más allá de los ya establecidos por la Norma internacional para la descripción bibliográfica de los libros antiguos (ISBD), la cual ha sido cuestionada por algunos bibliotecarios. Por otra parte, será necesario un estudio profundo de las ediciones para detectar si se trata de impresiones nuevas o de reimpresiones. 
En futuras investigaciones será necesario andar nuevamente el camino y revisar otras bibliotecas tanto nacionales como extranjeras que resguardan el libro del santo y de sus compañeros de orden, y que hayan pertenecido a instituciones mexicanas. Igualmente deberán revisarse los catálogos o repertorios escritos entre el siglo XVII y el siglo XX.

Será interesante de igual manera, detenerse en algunos de los jesuitas trabajados aquí y en otros personajes que no pertenecían a la orden, pero que realizaron textos basados en la obra de Íñigo, entre los cuales destacan los elaborados por clérigos seculares y por clérigos regulares como el cartujo Antonio de Molina, e incluso, por algunas mujeres.

Por último, debemos concluir y, quizá esto sea lo más relevante, que los ejercicios ignacianos, ya fueran siguiendo el libro del santo o de otros jesuitas fueron de gran relevancia en la vida espiritual de Nueva España y de la República Mexicana, no sólo por la práctica que de ellos hicieron diferentes sectores de la sociedad, sino por la amplia recepción que tuvieron las obras de otros jesuitas, e incluso, del libro del santo.

\section{Bibliografía}

Arzubialde Echeverría, Santiago, Ejercicios Espirituales de San Ignacio. Historia y análisis, Bilbao/Santander, Ediciones El Mensajero/Sal Terrae, 2009.

Calveras, José, "Estudios sobre la redacción de los textos latinos de los Ejercicios anteriores a la Vulgata", Archivum historicum Societatis Jesu, vol. XXXI, 1962, pp. 3-99.

, "Los textos latinos de los ejercicios anteriores a la vulgata, Archivum. Historicum Societatis, vol. XXXI, 1962, p. 5, pp. 3-99.

Campa, Pedro F. "La génesis del libro de emblemas jesuita”, Sagrario López Poza (Dir.), Literatura emblemática hispánica: Actas del primer simposio internacional, 1996, pp. 43-60.

Chartier, Robert y Daniel Roche, "El libro. Un cambio de perspectiva", en Jaques Le Goff y Pierre Nora (Dirs.), Hacer la historia, Barcelona, Laia, 1978-1980.

Chartier, Robert, El mundo como representación. Estudios sobre historia cultural, Barcelona, Gedisa, 1999.

Colección general de providencias hasta aqui tomadas por el gobierno sobre el extrañamiento y ocupación de temporalidades de los regulares de la compañia que existian en los dominios de S.M. de España, Indias e irlas Filipinas a conseqüencia del real decreto de 27 de febrero y pragmática sanción de 2 de abril de este año. Parte II, Madrid, Imprenta Real de la Gazeta, 1769.

Dalmases, Cándido de, Ignacio de Loyola. Ejercicios Espirituales, Cantabria, Sal Terrae, 1985.

Darton, Robert, El coloquio de los lectores. Ensayos sobre autores, manuscritos, editores y lectores, México, Fondo de Cultura Económica, 2003. 
Diccionario Histórico de la Compañía de Jesús. Bibliográfico-temático II, ed. Charles E. O’Neill y Joaquín María Domínguez, Madrid, Universidad Pontificia Comillas, 2001.

Diccionario Histórico de la Compañia de Jesús. Bibliográfico-temático, ed. Charles E. O’Neill y Joaquín María Domínguez Madrid, Universidad Pontificia Comillas, 2001, [pdf].

Febvre Lucien y Henri Jean Martin, L'apparition du libre, París, Albin Michael, 1958.

García Aguilar, María Idalia, "Entre el olvido y la supervivencia: Los libros jesuitas del colegio de San Luis Potosí”, Revista de El Colegio de San Luis, Nueva época, año VI, núm. 11, enero-junio de 2016, pp. 48-105.

DOI: https://doi.org/10.21696/rcs16112016432

García, Idalia y Ramón Aureliano Alarcón, "Bibliografía material para el conocimiento y trasmisión de las fuentes bibliográficas novohispanas" http:/iifilologicas. unam.mx/pnovohispano [Consultado el 5 de septiembre de 2020].

García de Castro Valdés, José "Los primeros de París. Amistad, carisma y pauta", Manresa. Revista de espiritualidad ignaciana, vol. 78, núm. 30, julioseptiembre, 2006, pp. 253-275.

Giménez López, Enrique, La Compañia de Jesús, del exilio a la restauración. Diez estudios, Alicante, Publicaciones de la Universidad de Alicante, 2017.

Giuliani Maurice, La experiencia de los ejercicios espirituales en la vida, Santander/ Sal Terrae, 1992. https://es.calameo.com/read/0033514789019a2d325fd [consultado el 29 de agosto de 2020].

Gómez Álvarez, Cristina, La circulación de las ideas. Bibliotecas particulares en una época revolucionaria. Nueva España, 1750-1819, Madrid, Trama editorial, 2019.

Gómez Álvarez, Cristina, Navegar con libros. El comercio del libro entre España y Nueva España (1750-1820), Trama editorial/unam, 2011.

González González, Enrique, Una república de lectores. Difusión y recepción de la obra de Juan Luis Vives, México, IISUE-UnAM, Plaza y Valdés, 2007.

González Migallón, Fernando, 150 años de las Leyes de Reforma, 1859-2009, México, UNAM, 2009.

Gray, James, "Praxis Exercitiorum Spiritualium P.S.N. Ignatti”, jamesgray2.wordpress. com.praxis-exercitiorum-spiritualium-p-s-n-ignatti [consulta el 30 de enero de 2020].

Índice último de los libros prohibidos y mandados a expurga: para todos los reinos y señoríos del catolico rey de las Españas, el Señor don Carlos IV, Madrid, en la imprenta de don Antonio de Sancha, 1790.

Iparraguirre, Ignacio, Práctica de los ejercicios de San Ignacio de Loyola en vida de su autor (1522-1556), Bilbao-Roma, El Mensajero del Corazón de Jesús/ Institutum Historicum Societatis Iesu, 1946.

, Orientaciones bibliográficas sobre San Ignacio de Loyola, Roma, Institutum Historicum Societatis Iesu, 1957.

,"El P. Luis de la Puente maestro de oración”, Manresa. Revista de espiritualidad Ignaciana, núm. 26, 1954, pp. 107-111. 
, Historia de la práctica de los Ejercicios Espirituales de San Ignacio de Loyola. Volumen I, Roma, 1973.

, "La oración en la Compañía naciente", Archivum Historicum Societatis Iesu, vol. XXV, pp. 455-487.

Leturia, Pedro,"Datos inéditos sobre la acción militar de Íñigo de Loyola en Pamplona" pp. 431-441. http://www.euskomedia.org/PDFAnlt/riev/21/21431441.pdf [Consultado el 28 de agsoto de 2020].

Lop, Miguel, Los directorios de ejercicios, 1540-1599, Santander, Ediciones Mensajero/Sal Terrae, 2000. https://books.google.com.mx/ books?id=VsJEAZEgshsC\&printsec=frontcover\&source=gbs_ge_ summary_r\&cad $=0 \# \mathrm{v}=$ onepage $\& \mathrm{q} \& \mathrm{f}=$ false, $[$ consultado el 29 de agosto de 2020].

Loyola, Ignacio, Exercicios Espirituales S. Ignacio de Loyola: con una introducción antes del texto del Santo, conveniente para formar el debido aprecio de estos exercicios, y la idea de su metodo y practica, Valencia, Joseph Estevan Dolz, 1733.

, Ejercicios espirituales de san Ignacio de Loyola, fundador de la Compañía de Jesús en su texto original, Barcelona, Imprenta y librería de Subirina hermanos, 1900.

McKerrow, Ronald, B, An Introduction to Bibliography for Literary Students, Oxford, Clarendon Press, 1927.

Moreno Gamboa, Olivia, La librería de Luis Mariano de Ibarra. Ciudad de México, 1730-1750, México, Educación y cultura 2009.

Muriel, Josefina, Los vascos en México y su colegio de las Vizcaínas, México, GIZATAM, 1987.

Obras de San Ignacio de Loyola, Madrid, Biblioteca de autores cristianos, 2013.

Pfeiffer, Heinrich, "El emblema de la Compañía de Jesús", Iconografía ignaciana. Cuadernos ignacianos 5, AUSJAL/Universidad Católica Andrés Bello, Caracas, 2004, pp. 11-18. DOI: https://doi.org/10.2307/j.ctv893j76

Rodríguez O., Hermann, "Peregrinación interior de Pedro Fabro", Theologica Xaveriana, núm. 160, 2006, pp. 641-664.

Rosignoli, Carlo Gregorio, Verdades eternas explicadas en lecciones ordenadas principalmente para los días de Exercicios Espirituales, México, Luis Abadiano y Valdés, 1843.

Rubial, Antonio, "Reseña del Libro, El discurso de la espiritualidad dirigida: Antonio Núñez de Miranda, Confesor de sor Juana", México, Nueva Revista de Filología Hispánica, vol. LIII, núm. 1, enero-junio 2005, pp. 241-245.

DOI: https://doi.org/10.24201/nrfh.v53i1.2267

Rubio Mañe, José Ignacio, El virreinato IV. Obras públicas y educación universitaria, México, Fondo de Cultura Económica/unam, 2005.

Vargas Cano de Santaya, Manuel, "La anotación 15a. de los ejercicios espirituales de San Ignacio. La rectitud de la intención del que da los ejercicios y su interpretación en algunos comentarios clásicos”, Madrid, Facultad de Teología, Universidad Pontificia de Comillas, 2017, Tesis de Doctorado. 